\title{
ANÁLISIS DEL MODELO TURÍSTICO DEL LITORAL GALLEGO DESDE EL ENFOQUE DE LA OFERTA
}

\section{Analysis of the tourist model of the Galician coast from the supply point of view}

\author{
Carlos Alberto Patiño Romarís \\ Universidad de Vigo
}

Recibido: $31 / 03 / 20$

Aceptado: 22/06/20

\section{Resumen}

El objetivo de este artículo es acercar una visión desde la óptica de la oferta del modelo de desarrollo territorial turístico del litoral gallego. Un análisis que consideramos obligatorio y continuado en el tiempo para los gestores de las OMDs (Organizaciones de Marketing de Destinos Turísticos) al objeto de poder tener un conocimiento los más exacto de la realidad territorial del producto turístico ofertado. Por el cual, profundizaremos en su análisis, contando con la limitaciones que imponen las escasas fuentes estadísticas existentes a nivel municipal, en los temas relativos a la oferta turística. Se trata de un sistema de oferta poco integrado en los circuitos comerciales y que espacialmente se plasma en modelos de ocupación extensivos, con predominio de un desarrollo inmobiliario de carácter secundario y lastrado por una fuerte estacionalidad. Ante esta realidad, los gestores de las diferentes OMDs del litoral gallego deben seguir apostando por el turismo desde un modelo de desarrollo sostenible. Un modelo en el que la oferta de alojamiento se oriente prioritariamente hacia

\begin{abstract}
The aim of this article is to bring a vision over from the optics of the offer of the model of territorial tourist development of the Galician littoral. An analysis that we consider obligatory and continued in the time for the managers of the OMDs (Organizations of Marketing of Tourist Destinations) in order to a knowledge is able to have them more exact of the territorial reality of the tourist offered product. For which, we will penetrate into his analysis, possessing the limitaciones that there impose the scanty statistical existing sources to municipal level, in the topics relative to the tourist offer. It is a question of a system of offer slightly integrated to the commercial circuits and that spatially it takes form of extensive models of occupation, with predominance of a property development of character secondary and ballasted by a strong seasonal variation. Before this reality, the managers of the different OMDs of the Galician littoral must continue betting for the tourism from a model developing sustainable. A model in whom the offer of housing is orientated as a priority towards the
\end{abstract}


las plazas de hotel de calidad, centrada en las estancias cortas basadas en productos turísticos de carácter diferenciador que reduzcan la estacionalidad y proporcionen un posicionamiento más favorable dentro del mercado de demanda.

\section{Palabras clave}

Espacio litoral, OMDs, producto turístico, sostenibilidad, diferenciación, imagen turística. squares of qualit hotel, centred on the short stays based on tourist products of character diferenciador that reduce the seasonal variation and provide a more favorable positioning inside the seller's market.

\section{Key words}

Coastal space, OMDs, tourist product, sustainability, differentiation, tourist image. 


\section{Introducción}

El objetivo de este artículo es acercar una visión del modelo de desarrollo territorial turístico del litoral gallego. Un análisis que debe ser de carácter obligatorio y continuado en el tiempo para los gestores de las OMDs al objeto de poder tener un conocimiento los más exacto posible de la realidad territorial del producto turístico ofertado con el objeto de poder posteriormente diseñar las estrategias idóneas de actuación. Por lo tanto, hablamos de tener un conocimiento profundo del modelo estructural del destino/producto litoral gallego ${ }^{1}$. Un primer acercamiento al análisis del destino litoral gallego nos llevó a la conclusión de que se comporta como un multidestino turístico basado en su diversidad morfoclimática y biogeográfica que condiciona la diversidad paisajística. Una realidad que nos determinó a estructurar el litoral gallego en nueve espacios turísticos (subdestinos) (Mapa 1)2. Cada uno de estos espacios turísticos, destino que individualizamos dentro del litoral gallego, aparece identificado por una o varias villas, ciudades o núcleos poblacionales que concentran el mayor número de atractivos, establecimientos turísticos o ambos, y constituyen también la referencia identificativa del espacio/destino para los mercados emisores ${ }^{3}$. Adicionalmente, cada espacio/destino diferenciado presenta una o varias puertas de entrada o salida ${ }^{4}$, utilizadas, sobre todo, en función de los mercados emisores y de las motivaciones de los turistas que se desplazan para visitarlo. La consideración de este acceso puede ser de singular relevancia para el planeamiento del litoral, puesto que la actividad turística está fundamentada en la accesibilidad a los mercados de demanda potenciales. Asimismo, estos desplazamientos de personas, desde su residencia habitual (mercados emisores) al destino, provocan

1 En esta dirección, son muy interesantes las aportaciones de Clare A. Gunn. Véase: GUNN, C. A. (1972): "Vacationscape: Designing tourist Regionans". Bureau of Business Research, University of Texas, Austin (USA). GUNN, C. A (1988): “Tourism Planing”. Taylor \& Francis, New York. GUNN, C. A (1993): “Tourism Palanning: Basics, Concepts, Cases”.Taylor \& Francis, Washington, D.C.

2 Una estructuración que cimentamos básicamente en tres criterios: vecindidad/continuidad geográfica, características tanto culturales como paisajísticas y la existencia de una imagen como un producto territorial diferenciado dentro de la demanda turística.

3 PLAN DE ORDENACIÓN DO LITORAL DE GALICIA (2010): TÍTULO II, CAPITULO 3: "A dinámica turística no litoral de Galicia”. Xunta de Galicia; op. cit. pág. 6.

http://www.xunta.es/litoral/web/index.php/descargables

4 Los gestores de las OMDs deben ser conscientes que estas puertas juegan un papel singular en la configuración de un destino, ya que constituyen el primer contacto con la demanda turística, indican el fin del desplazamiento más importante, dan una primera visión del destino y ayudan a la orientación de los viajeros hacia el interior del destino. Por lo tanto, las puertas son la primera imagen del destino y, a veces, lo que determina de forma esencial la percepción del destino dentro de la demanda. En consecuencia, las OMDs deberían tener en especial consideración su planificación y diseño. Ávial Bercial, R. y Barrado Timón, D. A. (2005): 41. 
un fuerte impacto sobre el transporte y la circulación en las áreas turísticas. Unos movimientos que también son internos a estos espacios/destinos turísticos, dando lugar a los itinerarios y a las rutas circulatorias, con efectos semejantes sobre la movilidad de diversa índole según el mes del año, según sea día laborable o de fin de semana y mismo la franja horaria del desplazamiento.

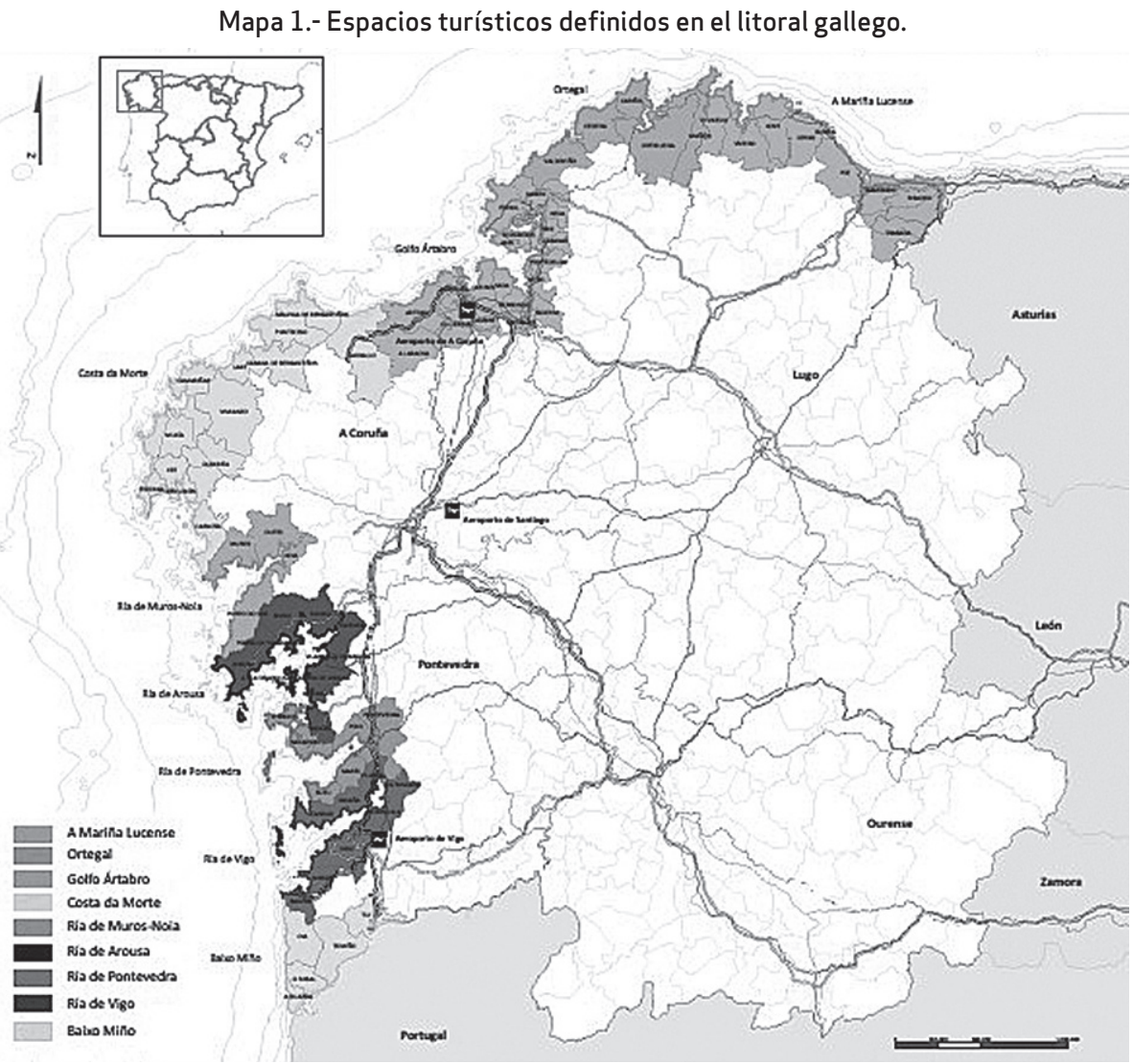

Fuente: Elaboración propia.

\section{La accesibilidad un factor estratégico para una política turística}

Las infraestructuras del transporte constituyen un factor capital para la dinamización y consumo de la actividad turística ${ }^{5}$. Así, son un "factor no pagado" por parte

5 Patiño Romaís, C. A. (2004a).

6 Biehl, D. (1988); Izquierdo de Bartolomé, R. (1989): 35-48; Argimón, I.; González-Páramo, J. M.; Martín, Ma . J. y Roldán, J. Mª . (1993); Argimón, I. y González-Páramo, J. M. (1997). 
de los agentes de producción turística de cara a posibilitar el consumo potencial de este tipo de actividad socio-productiva. Como es bien conocido, una oferta turística necesita del soporte infraestructural para su propio consumo. Esto es, el producto turístico debe ser disfrutado en un determinado lugar. Para eso, es necesario que se garantice el acceso de la demanda potencial hacia este concreto bien. De este modo, caemos en la cuenta del estratégico papel que juegan las infraestructuras del transporte y las comunicaciones en el binomio: oferta turística-demanda turística. Eso tanto es así que para lograr fomentar una política de mercadotecnia turística es clave disponer de una dotación de infraestructuras de comunicaciones y transportes modernas, ágiles y dinámicas. En pocas palabras, se necesitan que articulen a los principales focos emisores de la demanda potencial de turismo; que garanticen la fluidez y eficacia de los flujos hacia el bien turístico susceptible de ser comercializado; que exista una oferta de transporte multimodal acomodada a los perfiles del nivel adquisitivo de la demanda potencial; y que logren operar en el mercado de un modo integrado y especializado en unos competitivos estándares de accesibilidad. Es este uno de los indicadores que más fricciones puede originar a la política de dinamización turística fomentada desde las OMDs. De hecho, sin oferta de infraestructuras modernas, el éxito y la eficacia de la comercialización turística queda cuestionada por su propia base. En la actualidad este indicador viene a significar la facilidad con la cual la demanda de desplazamiento es capaz de cubrir un itinerario O-D por medio de una infraestructura de transporte y una modalidad determinada de desplazamiento.

La localización geográfica del territorio gallego en el cuadrante noroccidental de la Península Ibérica, durante mucho tiempo, le supuso una condición de periferia geográfica y económica. Una condición esta de periferia respecto ${ }^{7}$, como es lógico, de la localización territorial de los principales centros económicos y de decisión españoles y de la U.E. De hecho, durante una larga etapa histórica Galicia y buena parte de las CC. AA. de la fachada cantábrica padecieron un problema de enclavamiento territorial ${ }^{8}$. Una situación que le supuso a Galicia un acusado problema de accesibilidad territorial, a la hora de articular el mercado interior gallego respecto del mercado español. La producción final gallega, cuando era canalizada hacia los mercados, tenía que superar el notable condicionante de no disfrutar de unas infraestructuras de transporte y comunicación capaces de garantizar la fluidez de esta producción en unos tiempos de desplazamiento competitivos respecto de otras economías regionales ${ }^{9}$. La modernización de la red de carreteras en Galicia

7 González Laxe, F. I. (coord.) (1993): 64.

8 Labasse, J. (1987): 32.

9 Díaz Fernández, J. A. (2009). 
no experimentó un importante avance cualitativo hasta que no se procedió a efectuar la construcción de la malla viaria de alta capacidad de carga: red de autovías y autopistas. No obstante, este esfuerzo modernizador no se dejaría sentir en Galicia hasta la década de los años 70, con el proceso de construcción de la Autopista del Atlántico A Coruña-Vigo. El problema aquí fue el tiempo y el coste de oportunidad que le supuso a la economía gallega la realización de este eje viario. El último tramo de este corredor estructurante se logró concluir en el primero quinquenio de la presente centuria. En efecto, la realización de los tramos Fene-Ferrol y Vigofrontera portuguesa no se concluyeron hasta el año 2004.

Así pues, la primera infraestructura que contribuyó a fortalecer los niveles de accesibilidad territorial fue la Autopista del Atlántico AP-9 Ferrol-A Coruña-Santiago-Pontevedra-Vigo- Frontera Portuguesa. Este corredor originó la articulación territorial del sistema urbano gallego localizado en la Galicia Atlántica. Asimismo, posibilitó que la demanda potencial de movilidad hacia los productos turísticos gallegos experimentara una ganancia neta en estándares de accesibilidad territorial.

A pesar del gran avance que en materia de accesibilidad territorial conoció Galicia en virtud a la construcción de este eje viario, no podemos dejar de indicar que el resto del territorio gallego se encontraba disfrutando de unos niveles de accesibilidad muy bajos. Esta situación no cambió diametralmente a mejor hasta que no se produjo la llegada del Estado de las Autonomías. En esta etapa histórica se potenció un modelo de organización territorial destinada a lograr la cohesión económica y social del territorio español. Se pretendía ahora corregir los desequilibrios territoriales en materia de dotación de infraestructuras, y por lo tanto, de dotación de conectividad territorial. Para eso, la planificación indicativa resultante en materia de infraestructuras había apostado con fuerza por la construcción de una malla viaria de alta capacidad de carga destinada a incrementar ostensiblemente los estándares de accesibilidad territorial. El gran paso para lograr este presupuesto fue la aprobación del Plan Director de Infraestructuras del Transporte ${ }^{10}$. En esta política de infraestructuras se propuso dotar a los territorios regionales de una articulación territorial mediante autovías. Para el caso de Galicia, que es quien capitaliza nuestro interés, se programaron dos estructurantes ejes viarios:

- La Autovía del Noreste A-6 A Coruña-Lugo-Benavente.

- La Autovía de las Rías Baixas A-52 Vigo-Ourense-Benavente.

En línea con esta inercia inversora hay que ver también el interés por potenciar las relaciones transfronterizas entre España y los países fronterizos. Para Galicia, fue un hito clave la permeabilización transfronteriza Galicia-Región Norte

10 MOPTMA (1993): "Plan Director de Infraestructuras, 1993-2007”. Ministerio de Obras Públicas, Transportes y Medio Ambiente (MOPTMA), Madrid. 
de Portugal. Con cargo al presupuesto del PDI se logró impulsar la construcción del puente internacional sobre el Miño Tui-Valença do Minho, el puente entre O Rosal-Vilanova de Cerveira, el puente entre Salvaterra do Miño y Melgaço, etc.

El resultado para la actividad turística no se hizo esperar. Progresivamente se fue detectando un proceso de mayor afluencia a Galicia por motivos de turismo. Los notables avances en materia de inversión de infraestructuras viarias de titularidad del Estado se fueron completando con el proceso de construcción y entrada en servicio de las infraestructuras viarias que logró construir la Xunta de Galicia. Esta modernización viaria contribuiría, progresivamente en el tiempo, a completar la malla viaria gallega para dotarla de unos crecientes estándares de accesibilidad territorial (Mapa 2). Una red viaria que había sido diseñada para lograr la articulación territorial de las cabeceras de comarca respeto del sistema de ciudades de Galicia. Los efectos deducidos de estas inversiones en infraestructuras se dejaron sentir pronto. Por una parte, se logró vertebrar y articular mejor el mercado interior gallego. En segundo lugar, articular el mercado gallego respeto del mercado interior español. En esta misma línea, se consiguió que las CC. AA. limítrofes con Galicia (Asturias y Castilla-León), además de la Región Norte de Portugal, experimentaran un sustancial incremento en sus niveles de flujo viario hacia ambos lados de los límites fronterizos.

En último término, en la política indicativa de la Administración del Estado se había apostado por potenciar la cadena intermodal del transporte. Así, en el PDI se habían fijado las bases para la modernización funcional y operativa del ferrocarril, el sistema aeroportuario y la red portuaria. La modernización ferroviaria había sido planificada en razón al cambio del ancho de vía. Se había propuesto ahora impulsar la construcción de una red de ferrocarriles dotada de ancho internacional (AI) y operativa en régimen de Alta Velocidad (AV) para conectar al sistema territorial español. No obstante, la modernización ferroviaria no se logró efectuar en Galicia hasta fechas relativamente recientes. En el PDI se habían fijado las bases para impulsar la modernización estructural de esta infraestructura del transporte. No obstante, no se articula la salida hacia Francia ni Portugal. Por otra parte, las características técnicas de la modernización ferroviaria nos aclaran que las CC. AA no tendrían un servicio ferroviario de AV, toda vez que estaba previsto modernizar la línea férrea convencional. Así, la planificación indicativa del Plan de Infraestructuras y Transporte ${ }^{11}$ había apostado decididamente por impulsar la conexión ferroviaria en régimen de Alta Velocidad. El problema fue que las características técnicas con las que se proyectó la modernización ferrovia-

11 MINISTERIO DE FOMENTO (2002): "Plan de Infraestructuras y Transporte (PIT) 20002010”. Ministerio de Fomento, Madrid. 
ria suponía pocos avances para territorios regionales como Galicia. Además, esta planificación había conocido numerosas correcciones en sus estándares de accesibilidad territorial ${ }^{12}$. De hecho, se le llegó a acusar mismo de un Plan improvisado. En consecuencia, las relaciones de la matriz de viaje O-D Madrid Galicia estaban fijadas en 4 horas Madrid-A Coruña y 3:50 para Madrid-Vigo. Así, la planificación del Plan Estratégico de Infraestructuras y Transporte $(\text { PEIT })^{13}$ fue diseñado para lograr una operatividad ferroviaria capaz de impulsar una modernización al conjunto de la malla española. Los estándares de accesibilidad territorial iban a experimentar un sobresaliente avance. Los tiempos de viaje entre Galicia y Madrid pasarían a quedar fijados en el orden de las 2 horas. Para eso, la Administración del Estado planificó la Variante Norte o del Guadarrama. Este corredor sería lo que se bifurcaría para articular las CC.AA septentrionales: Galicia, Asturias, País Vasco, juntamente con Castilla-León. La modernización impulsada a esta infraestructura iba a garantizar que se lograra una operatividad Madrid-Ourense a unas velocidades de $300 \mathrm{~km} / \mathrm{h}$ (Alta Velocidad). El problema para la articulación de Galicia reside en el tramo Ourense-Lubián-Puebla de Sanabria. Este tramo tiene un importante desnivel que condiciona en extremo las velocidades comerciales ferroviarias. La última planificación indicativa había propuesto que los tráficos pudieran circular aquí a $200 \mathrm{~km} / \mathrm{h}$. Este registro mejoraba en mucho el propuesto por el PIT que era únicamente de $90 \mathrm{~km} /$ hora. En el marco de la ejecución inversora propuesta por el PEIT nos encontramos con la modernización de dos importantes ejes en Galicia. Por un lado, la puesta en servicio del eje ferroviario Ourense-Santiago en régimen de Velocidad Alta. Esta línea ferroviaria es la única que puede alcanzar una Velocidad Alta $(300 \mathrm{~km} / \mathrm{h})$. En paralelo, la prestación de servicio se vio hace poco acompañada de la conclusión del corredor atlántico Vigo-A Coruña. Estos dos itinerarios ferroviarios están experimentando unos importantes crecimientos en el montante de viajeros transportados por cada sentido del tráfico. Esta oferta de transporte contribuyó de manera destacada a potenciar la oferta turística gallega, al articular optimamente los diferentes productos turísticos con el mercado interior gallego. No obstante, la conexión de Galicia con la Meseta, en régimen de Alta Velocidad, se va a demorar hasta inicios del 2021. Esta fecha fue ya pospuesta en numerosas ocasiones. La conclusión de esta infraestructura originará, en lo que afecta al turismo, una capacidad de atracción hacia los productos turísticos gallegos. Los niveles de accesibilidad territorial, juntamente

12 El Informe Viaria fue presentado por parte del Ministro de Fomento en las diferentes CC.AA. Las aportaciones de este informe no hacían otra cosa que modificar las propuestas de accesibilidad territorial consideradas en el borrador del PIT.

13 MINISTERIO DE FOMENTO (2005). "Plan Estratégico de Infraestructuras y Transporte (PEIT) 2005-2020”. Ministerio de Fomento, Madrid. 
con la política tarifaria, los patrones de la oferta de viaje (confort, comodidad, seguridad, etc.), originarán en el horizonte próximo una importante afluencia de turistas a Galicia.

Mapa 2.- Distribución espacial de la red de carrteras en Galicia. Año 2015.

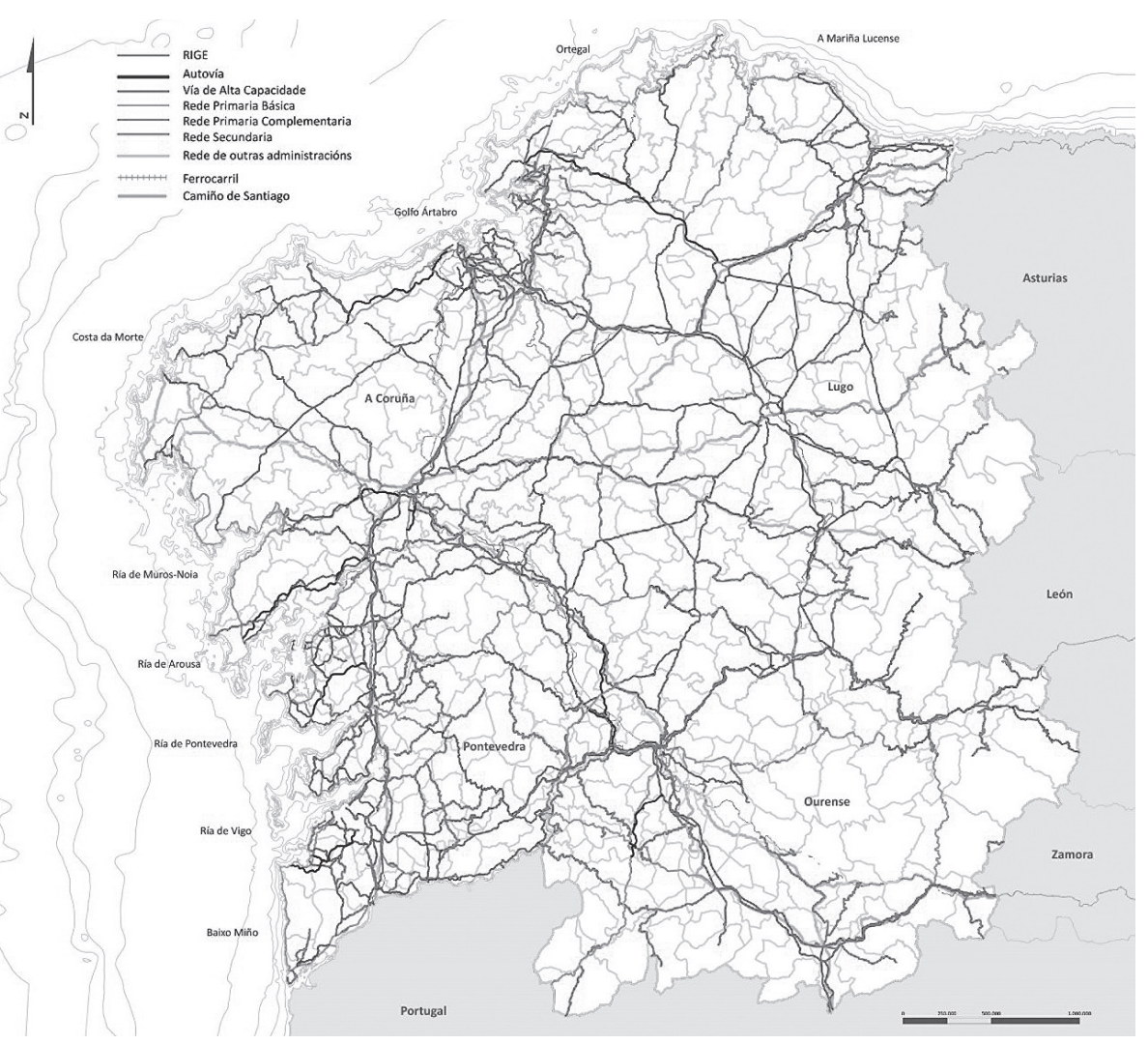

Fuente: Elaboración propia.

En esta misma línea, cabe apuntar que en el marco de la política comunitaria del transporte se podrá modernizar este tipo de infraestructura para articular las regiones transfronterizas ${ }^{14}$. Para el concreto caso de Galicia, la posibilidad de modernizar la línea Vigo-Guixar-Oporto será capital. La modernización de la infraestructura y la prestación de servicio efectuada mediante línea de ancho internacional y con material rodante de última generación lograrán dos efectos direc-

14 En efecto, las Redes Transeuropeas del Transporte (RTE-T) proponen fomentar las relaciones trasnacionales entre los países miembros. En este sentido, este modelo de política transeuropea del transporte se fijó en el Consejo de Essen con la redacción de los 14 Proyectos que fueron coordinados por el Van Miert. 
tos. Por un lado, fortalecer los estándares de accesibilidad territorial de Galicia R. N. P. por vía ferroviaria. En la actualidad, los tiempos de viaje que se producen entre Oporto y Vigo no son en nada competitivos. La duración de este itinerario está fijada en tres horas, toda vez que la velocidad comercial media de este itinerario es de $57 \mathrm{~km} / \mathrm{h}$. Este indicador contrasta mucho con el obtenido por la carretera: una hora de viaje de promedio. Por otra parte, se fortalecerá en amplia medida la dotación de servicios hacia una dirección y a otra. En la actualidad solo se producen dos expediciones diarias desde Vigo. La demanda de viaje que se moviliza por esta modalidad es totalmente marginal. Esta realidad debe ser corregida con urgencia en el marco de la política comunitaria del transporte. En segundo lugar, se logrará articular mejor al sistema de ciudades de la Eurorregión y, en paralelo, del Eje Atlántico Peninsular.

Finalmente, en el territorio gallego se encuentran en funcionamiento tres aeropuertos regionales (Alvedro en A Coruña, Rosalía de Castro en Santiago de Compostela y Peinador en Vigo) que comercializan su oferta regular de servicio con las principales ciudades españolas (mercado doméstico), así como con las principales ciudades europeas. En esta línea, el aeropuerto gallego que ostenta una proyección más internacional es el de Rosalía de Castro (Santiago de Compostela), toda vez que posee un mayor nivel de conexiones con aeropuertos del extranjero. Con todo, las principales conexiones internacionales nos vienen dadas después de conexión con los "hubs" aeroportuarios de Barajas (Madrid) y del El Prat (Barcelona). No obstante, y al efecto de no generar un sesgo en el estudio de los modelos de flujo de oferta/demanda de viaje por vía aeroportuaria, cabe apuntar que el aeropuerto de Sá Carneiro (Oporto) está captando una interesante demanda de viajeros con el O-D en Galicia, en razón a su atractiva política comercial vía precios y vía ventajas comparativas. De hecho, está implementando una política comercial tal que logra atraer a la demanda potencial de viaje gallego hacia esta terminal gracias a que dotaron de una oferta de conectividad con las principales ciudades gallegas, mediante vehículo colectivo de viajeros que le resulta muchas veces gratuito a la demanda de viaje.

\section{Análisis de la infraestructura turística del litoral gallego}

Una de las primeras cuestiones a aclarar es definir ¿que entendemos por infraestructura turística? Empezaremos señalando que para calcular la oferta turística de un destino hay que tener presente las peculiaridades del sector. En este sentido, un porcentaje significativo de empresas son habitualmente catalogadas como "turísticas" por la actividad que realizan, aunque ofrecen sus productos también a los 
residentes. Por eso, es difícil el planteamiento de una delimitación de lo que es una empresa/equipación turística. Obviamente, el punto lógico de partida sería considerar dos variables: la función que cumplen sus productos y el mercado al que van dirigidos. Se acostumbra a considerar, no obstante, que la empresa/equipamiento turístico, es aquél que desempeña una posición en el proceso de satisfacción de las necesidades de los consumidores turísticos a través de la configuración de productos turísticos dentro de un destino. El concepto producto turístico se extiende a todas las actividades que tienen lugar desde la realización de una reserva hasta cualquier contacto posterior a la entrega y consumo del producto, ampliando la unidad de análisis desde la empresa al destino turístico. Por lo tanto, consideraremos la infraestructura turística como el conjunto de equipaciones e instalaciones que hacen posible la permanencia del visitante en una localidad. En este concepto se incluye tanto la oferta básica como la complementaria.

La infraestructura turística en el litoral gallego está conformada tanto por las equipaciones básicas de carácter general y las infraestructuras de transporte como por la infraestructura de alojamiento. Los gestores de las OMDs deben saber que la oferta de alojamiento es uno de los factores fundamentales que identifican a un espacio como destino turístico. Las diferencias en la estructuración interna de la oferta, atendiendo su tipología y calidad, determina fundamentalmente el tipo de demanda potencialmente captable. Por el cual, profundizaremos en su análisis, contando con las limitaciones que imponen las escasas fuentes estadísticas existentes a nivel municipal, en los temas relativos a la oferta turística.

\subsection{Análisis de la oferta turística básica del litoral gallego}

Las empresas dedicadas a proporcionar alojamiento son un componente esencial de la oferta básica del sector turístico. El objeto específico del presente apartado es el análisis del mercado de alojamiento en los diferentes destinos del litoral gallego. A este respecto, cabe precisar que, en general, el conjunto de medios de alojamiento disponibles se puede dividir en dos grandes grupos: reglada y no reglada. Dentro de la oferta de alojamiento reglada podemos, a su vez, diferenciar entre los establecimiento de tipo hotelero (hoteles, hoteles-apartamento, pensiones, etc.), y los de tipo extrahotelero (campings, apartamentos, casas de turismo rural, etc). Por su parte, dentro de la oferta no reglada vamos a considerar básicamente a las viviendas de carácter secundario. Ahora bien, nuestro análisis del componente alojamiento del producto turístico litoral gallego lo vamos a centrar en el estudio de la oferta hotelera y en las residencias secundarias.

En lo que respeta al conjunto de la oferta reglada, empezaremos señalando que en el año 2012, el análisis del total de plazas disponibles situaba a Galicia por de- 
bajo del promedio español, en términos de plazas por habitante: 0,03 frente a las 0,05 por habitante en España. Concretamente, Galicia concentraba el 3,58\% de las plazas del total del estado.

A nivel provincial en el año 2012, según los datos registrados en la Secretaría General para el Turismo, Pontevedra (41,00\%) y A Coruña $(36,44 \%)$ localizaban el mayor peso de la oferta (Cuadro 1). Especialmente signficativo es el peso de la oferta de plazas en hoteles de Pontevedra $(47,80 \%)$ dentro del territorio gallego. Por su parte, el espacio litoral gallego concentraba en su conjunto un total de 82.822 plazas de oferta reglada, un volumen que suponía el 63,84\% del total en Galicia. A su vez, dentro de las diferentes tipologías de establecimientos destacaba el peso alcanzado por los campings (86,95\%), apartamentos $(80,74 \%)$ y hoteles $(65,07 \%)$, dentro del territorio gallego. Obviamente, estamos con unas tipologías de oferta, especialmente las dos primeras, que responden tradicionalmente a las expectativas de alojamiento de un gran número de demandantes del producto de "sol y playa". Eso sí, tipologías orientadas a diferentes segmentos de demanda en cuanto a la forma de organización del viaje, y a la capacidad adquisitiva. Entre los diferentes espacios turísticos en los que hemos segmentado el litoral gallego destacan, por el tamaño de su oferta reglada, los que se indican en el siguiente orden: Ría de Pontevedra (23.672 plazas, 18,25\% total Galicia), Golfo Ártabro (15.503 plazas, 11,95\% total Galicia) y Ría de Vigo (14.002 plazas, 10,79\% total Galicia).

\begin{tabular}{|c|c|c|c|c|c|c|c|}
\hline \multicolumn{8}{|c|}{$\begin{array}{l}\text { Cuadro 1. Oferta total de plazas regladas por tipología de establecimiento en Galicia, a escala } \\
\text { provincial y en el total de los municipios del litoral gallego. } \\
\text { Año } 2012^{2} \text {. }\end{array}$} \\
\hline & A & B & C & D & E & Total & $\%$ \\
\hline Galicia & 55.795 & 27.066 & 7.260 & 34.929 & 4.673 & 129.727 & 100 \\
\hline A Coruña & 18.218 & 12.630 & 2.002 & 13.149 & 1.275 & 47.275 & 36,44 \\
\hline Lugo & 6.443 & 7.254 & 2.015 & 3.225 & 773 & 19.711 & 15,19 \\
\hline Ourense & 4.464 & 2.491 & 1.064 & 1.190 & 347 & 9.556 & 7,37 \\
\hline Pontevedra & 26.670 & 4.691 & 2.179 & 17.365 & 2.278 & 53.184 & 41,00 \\
\hline LITORAL & 36.304 & 10.475 & 1.935 & 30.335 & 3.773 & 82.822 & 63,843 \\
\hline GALLEGO & & & & & & & \\
\hline
\end{tabular}

(A) Hoteles; (B) Pensiones1; (C) Turismo Rural; (D) Campings; (E) Apartamentos.

Fuente: Elaboración propia a partir del Directorio de empresas e actividades turísticas, Secretaría Xeral para o Turismo, Consellería de Cultura e Turismo.

${ }^{1}$ La categoría "Pensiones" engloba los Albergues Turísticos. ${ }^{2}$ Datos referidos al 31 de diciembre. ${ }^{3}$ Sobre total Galicia. 
La evolución mensual de la oferta de plazas en establecimientos hoteleros presenta una marcada estacionalidad en Galicia. El carácter predominantemente estival de la oferta hotelera de los destinos de "sol y playa" localizados en la Ría de Pontevedra explica la fuerte oscilación de la oferta. Sanxenxo, de los destinos analizados en la Gráfico 1, refleja una mayor variación a lo largo del año en su oferta. De hecho, la oferta del mes de diciembre operativa (1.642 plazas) representaba solo un $18,89 \%$ de la oferta de agosto (8.694 plazas). Esta estacionalidad va ligada, en buena parte de los casos, a la existencia de pequeños establecimientos de categorías de una y dos estrellas, que se incorporan al mercado exclusivamente en temporada alta. Por lo tanto, podemos concluir que estos trazos son una respuesta lógica a las características de la demanda hotelera para cada uno de los destinos turísticos que se pueden delimitar en Galicia. La ausencia de destinos de carácter litoral relevantes en las provincias de Lugo y Ourense, salvo la excepción del caso de la Mariña Lucense, da lugar a la carencia de una fuerte oscilación en la oferta.

\section{Gráfico 1. Evolución mensual de la oferta de plazas hoteleras en los principales destinos del litoral gallego y Santiago de Compostela. Año 2012.}

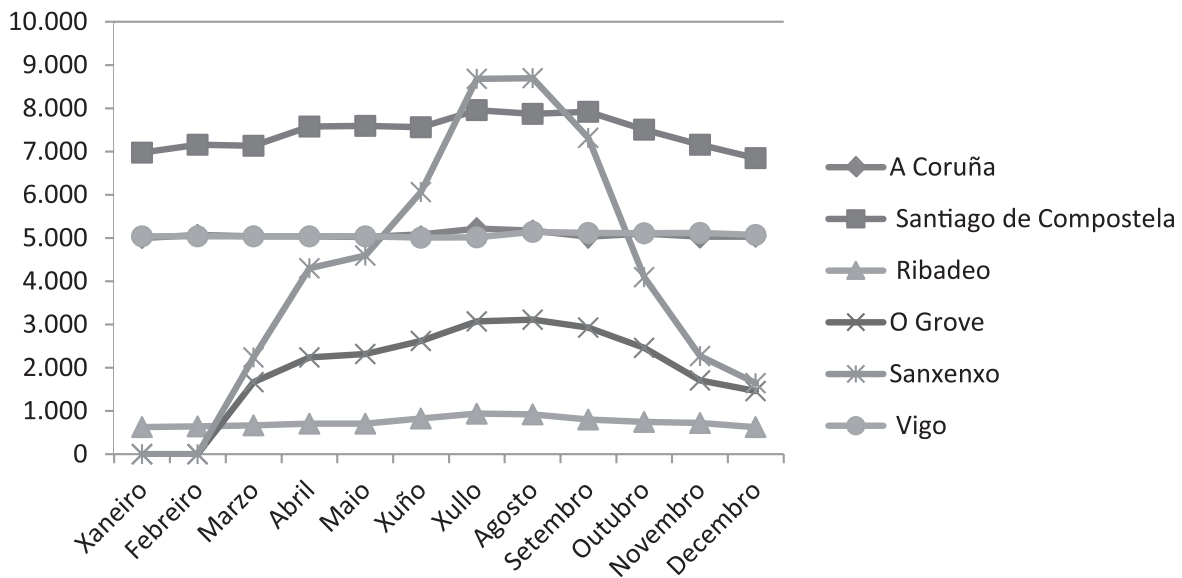

Fuente: Elaboración propia a partir de la Encuesta de Ocupación Hotelera (EOH)-INE.

*Dato no disponible para los meses de enero y febrero en los casos de O Grove e Sanxenxo.

Una primera lectura de estos datos permitiría afirmar que, en términos relativos respeto al resto de los destino turísticos españoles, en Galicia y especialemente en su litoral existe una relativa sobreoferta. No obstante, es preciso tener en cuenta que los elevados niveles de actividad del sector turístico que registra el mercado español resaltan especialmente (en términos comparativos) la infrautilización de la capacidad del sector hotelero gallego. Por otro lado, la interacción entre actividad hotelera y turística debe matizar esta afirmación. La demanda hotelera es clara- 
mente dependiente de la turística, pero, igualmente, la demanda de un determinado destino turístico está también claramente ligada a la oferta hotelera en este ${ }^{15}$.

\subsection{1.- Características de la oferta hotelera en el litoral gallego}

El análisis de las características de los establecimientos hoteleros gallegos ponen de manifiesto una calidad inferior al promedio de España. De hecho, si empleamos como criterio de medición de la calidad de la oferta hotelera el porcentaje de hoteles de cuatro y cinco estrellas, Galicia se encuentra por debajo del promedio español (5,58\% de establecimientos frente al 14,83\% de España). En este sentido, Galicia es la región costera que se sitúa a la cola tanto en calidad como en dimensión de los establecimientos. Ello es así hasta el punto de que su perfil se ajusta más al característico de las regiones interiores que no se consideran fuertemente penetradas por el turismo. En lo que respecta, en concreto, a la distribución provincial de la oferta de hoteles de cinco estrellas en Galicia, cabe señalar el peso predominante de A Coruña con el 55,56\% (Cuadro 2). La explicación de esta concentración se debe a que Santiago de Compostela contabiliza 4 de los 9 establecimientos gallegos. Una oferta que responde a un perfil de demanda urbano-cultural. Por su parte, en el conjunto del litoral nos encontramos con 4 establecimientos de cinco estrellas. No obstante, debemos señalar que dentro de este conjunto solamente el "Gran Hotel La Toja" (O Grove) se localiza fuera de las ciudades de Vigo y A Coruña. Se trata de un establecimiento ligado en sus orígenes a la explotación de las aguas termales de la isla de A Toxa, actividad inciada ya avanzado el siglo $\mathrm{XIX}^{16}$. Un hecho que nos apunta al predominio de un segmento de demanda de perfil adquisitivo medio-bajo dentro de la oferta hotelera del litoral gallego. En esta dirección, también apunta que dentro del conjunto del litoral son los hoteles de una estrella los más númerosos con 212 establecimientos $(63,10 \%$ del total de Galicia).

Dentro de los diferentes espacios turísticos establecidos en el del litoral gallego, destaca ampliamente por su oferta de hoteles la Ría de Pontevedra, con 209 hoteles en las diferentes categorías (37,66\% y 23,51\% del total del litoral y Galicia, respectivamente). Dentro de esta oferta predominan los hoteles de dos (71 establecimientos) y una estrella (77 establecimientos). Un hecho que se repite en Sanxenxo, principal centro hotelero del litoral gallego, con 45 hoteles en cada una de estas dos categorías. Se trata de una oferta orientada básicamente al producto "sol y playa".

15 Santos Solla, X. M. (coord.); Castellanos García, P.; Dopico Castro, J. Á. y Pena López, J. A. (2007): 57.

16 PATIÑO ROMARÍS, C. A. (2002a): 15-21. 


\begin{tabular}{|c|c|c|c|c|c|c|c|c|c|c|c|c|}
\hline & Total & $\%$ & $5^{*}$ & $\%$ & $4^{*}$ & $\%$ & $3^{*}$ & $\%$ & $2^{*}$ & $\%$ & $1^{*}$ & $\%$ \\
\hline Galicia & 889 & 100 & 9 & 100 & 97 & 100 & 146 & 100 & 301 & 100 & 336 & 100 \\
\hline A Coruña & 267 & 30,04 & 5 & 55,56 & 35 & 36,08 & 45 & 30,82 & 86 & 28,57 & 96 & 28,57 \\
\hline Lugo & 122 & 13,72 & 1 & 11,11 & 15 & 15,47 & 16 & 10,96 & 39 & 12,96 & 51 & 15,18 \\
\hline Ourense & 90 & 10,12 & 0 & 0,00 & 12 & 12,37 & 10 & 6,85 & 20 & 6,64 & 48 & 14,29 \\
\hline Pontevedra & 410 & 46,12 & 3 & 33,33 & 35 & 36,08 & 75 & 51,37 & 156 & 51,83 & 141 & 41,96 \\
\hline $\begin{array}{l}\text { LITORAL } \\
\text { GALLEGO2 }\end{array}$ & 555 & 62,43 & 4 & 44,44 & 54 & 55,67 & 100 & 68,49 & 185 & 61,46 & 212 & 63,10 \\
\hline
\end{tabular}

Fuente: Elaboración propia a partir del Directorio de empresas e actividades turísticas ${ }^{1}$, Dirección Xeral para o Turismo, Consellería de Cultura e Turismo. "Guía de Aloxamentos Turísticos 2013: Hoteis"2. TURGALICIA, Xunta de Galicia.

${ }^{1}$ Datos referidos al 31 de diciembre de 2012. ${ }^{2}$ Datos referidos al 30 de septiembre de 2012.

Otro de los trazos más destacables de los establecimientos hoteleros tanto en el litoral como en el resto del territorio gallego es su reducida dimensión. En general, se trata de establecimientos que no superan las 70 plazas, lo que sitúa a Galicia nuevamente a la cola de las CC. AA. Únicamente Asturias presenta un promedio de tamaño inferior en sus hoteles $(49,35)$. A nivel provincial, y siempre siguiendo en este caso al Directorio de Empresas y Actividades Turísticas (DEAT) de la Dirección General para el Turismo, las medias más elevadas de tamaño de los hoteles se registran en las tres provincias del litoral: A Coruña (68,23 plazas/ hotel), Pontevedra (65,05 plazas/hotel) y Lugo (52,81 plazas/hotel). Ourense, por el contrario, registra el valor más bajo $(49,60)$. Un hecho que debemos ligar esencialmente a dos realidades. Por un lado, ser el territorio gallego menos dinámico económicamente. Por el otro, la dotación de una oferta de productos turísticos de carácter poco masificado (turismo cultural, turismo de salud, turismo etnográfico, etc.). En esta dirección, resulta lógico que el conjunto del litoral gallego presente un tamaño medio en su oferta de hoteles superior a todas las demarcaciones provinciales (70,84 plazas/hotel). Dentro de este, los espacios turísticos con medias más elevadas son el Golfo Ártabro $(109,15)$ y la Ría de Vigo $(81,14)$, precisamente donde se localizan las ciudades de A Coruña $(159,36)$, Ferrol $(102,00)$ y Vigo $(101,18)$. Por su parte, el principal espacio turístico del litoral gallego: la Ría de Pontevedra $(68,90)$, como sus principales destinos: O Grove $(75,40)$, Poio $(68,52)$, Pontevedra $(74,93)$ y Sanxenxo $(72,26)$, reflejan valores superiores a los promedios provinciales, pero no dejan de mostrar una baja media. Esta insuficiencia en el tamaño lleva consigo una reducida capacidad para lograr economías de escala y alcance. Es decir, limita las posibilidades de reducir los 
costes unitarios en la prestación de servicios y de proporcionar nuevos paquetes de servicios turísticos más amplios.

Estas carencias relativas a la categoría y dimensión a las que aludimos tanto en el conjunto de Galicia como en su ámbito litoral, objeto de nuestra análisis, pueden explicarse en buena medida por la forma de propiedad predominante y la escasa penetración de las cadenas hoteleras. En general, a raíz del análisis efectuado en el litoral gallego, los gestores de las diferentes OMDs deben ser conscientes de que la oferta se caracteriza por un elevado número de establecimientos de pequeña dimensión, gestionados en muchos casos por sus propietarios. Los objetivos de este tipo de establecimientos se centran más bien en la supervivencia, (garantizando unas rentabilidades mínimas) que en el crecimiento, como ponen de manifiesto sus bajos niveles de inversión. Una situación que debe determinar una clara línea de actuación desde las OMDs del litoral gallego dirigida a fomentar la colaboración de los diferentes agentes empresariales del sector hotelero en busca de sinergias encaminadas a lograr una mayor eficiencia y eficacia en la gestión de sus establecimientos.

\subsubsection{La " $Q$ " de Calidad Turística como elemento distintivo de gestión dentro de la oferta reglada del litoral gallego}

La necesidad en la diferenciación del producto ofertado al cliente, siempre tomando como referente la calidad de este, condujo a una porgresiva aplicación de las tecnologías de calidad en los establecimientos reglados de alojamiento tanto en el ámbito español como en el gallego. Entre estos sistemas el más conocido dentro de la demanda es la "Q" de Calidad Turística. Una marca de calidad otorgada por el Instituto para la Calidad Turística (ICTE) ${ }^{17}$. En el año 2012, dentro de la oferta reglada de alojamiento, Galicia contaba con 112 establecimientos distinguidos con la "Q" de calidad. Un total de 6.786 plazas que suponían el 5,23\% de la oferta total (Gráfico 2). Un promedio que únicamente era superado por las provincias de Lugo (7,66\%) y Ourense (8,38\%). El conjunto del litoral gallego presentaba un total 51 establecimientos con 3.685 plazas (4,46\% de la oferta total). Dentro de las difrentes tipologías de establecimientos, debemos resaltar que son los hoteles los que concentran prácticamente toda la oferta dotada de "Q" de Calidad en Galicia (75,33\% de las plazas) como en sus provincias: A Coruña (41,83\%), Lugo (85,70\%),

17 El ICTE es un organismo privado e independiente de certificación de Sistemas de Calidad especialmente creados para empresas turísticas, formado por las asociaciones turísticas nacionales, la Secretaría de Estado de Turismo, las CCAA y la Federación Española de Municipios y Provincias (FEMP). Una entidad encargada básicamente de certificar, administrar y velar por el correcto uso de la Marca "Q". Para una mayor información consultar: http://www. calidadturistica.es/motor.php?id_pagina $=$ menu/que es 
Ourense (94, 38\%) y Pontevedra (93,27\%). Los hoteles certificados con "Q" de calidad en el litoral gallego representaban 2.546 plazas (69,09\% del total de las plazas certificadas). El espacio turístico litoral con más hoteles (10) y habitaciones (654) distinguidos con la "Q" de calidad es la Ría de Pontevedra. Un volumen de plazas que suponen el 9,08\% del total de habitaciones ofertadas en este espacio litoral. Un promedio que es superado por el Baixo Miño (18,97\%), Mariña Lucense (12,99\%) y Costa da Morte (11,13\%). Por el contrario, la Ría de Muros-Noia carece de oferta hotelera certificada.

Si atendemos a la categoría de los establecimientos, los hoteles de 5 y 4 estrellas certificados son 22 en todo el litoral gallego. Una cifra que supone el 84,61\% y $92,93 \%$ del total de hoteles y habitaciones con "Q" de calidad, respectivamente. Un hecho significativo que debemos vincular a dos premisas. Por una parte, a la relativa complejidad de la obtención de este tipo de certificaciones de calidad. Por otro lado, al carácter minufundista y familiar de gran parte de la oferta de hoteles del litoral. Una última premisa que nos traslada también al problema general de la baja formación y capacitación en los gestores de estas empresas.

\section{Gráfico 2. Oferta total de establecimientos reglados distinguidos con la "Q" de Calidad Turística por tipología de establecimiento en Galicia. Año 2012. Unidad: \% sobre total plazas ${ }^{1}$ en cada territorio ${ }^{2}$.}

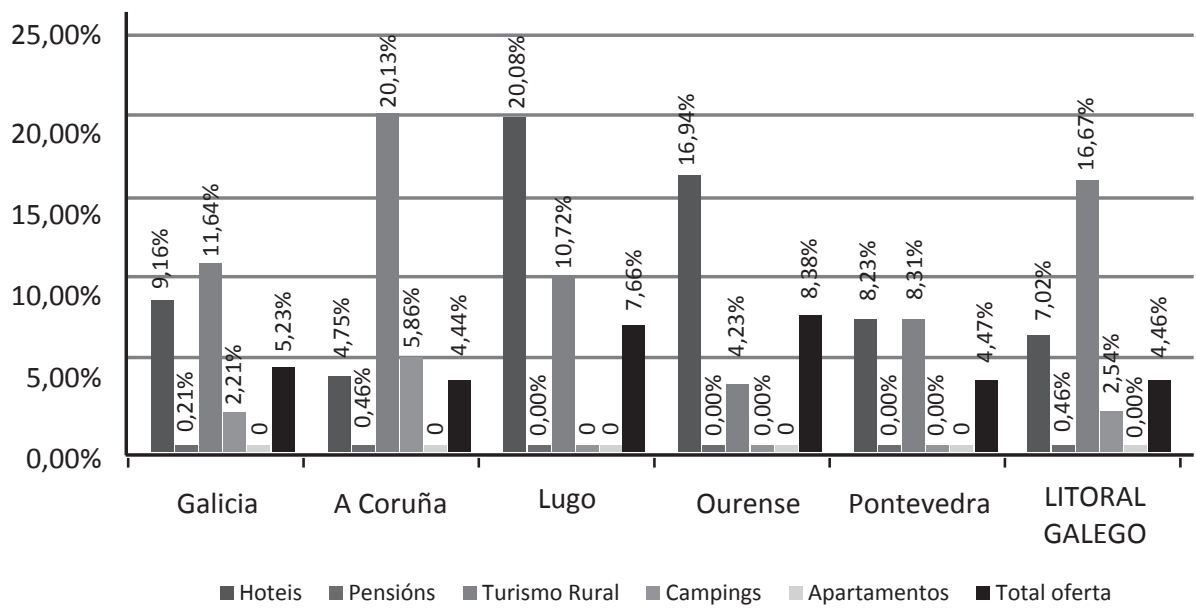

Fuente: Elaboración propia a partir de la "Guía de Aloxamentos Turísticos 2013: Hoteis". TURGALICIA, Xunta de Galicia. Datos referidos al 30 Septiembre de 2012. "Guía de Aloxamentos 2013: Turismo Rural". TURGALICIA, Xunta de Galicia. Datos referidos al 1 de Septiembre de 2012. "Guía de Aloxamentos 2013: Campings". Datos referidos al 30 Septiembre de 2012. Directorio de empresas e actividades turísticas, Dirección Xeral para o Turismo, Consellería de Cultura e Turismo. Datos referidos al 31 de Diciembre de 2012. ${ }^{1}$ Los datos disponibles de la oferta de hoteles desagregada a nivel municipal en la "Guía de Aloxamentos Turísticos 2013: Hoteis" y en la "Guía de Aloxamentos 2013: Turismo Rural” propocionan únicamente datos a nivel de número habitaciones. En función de lo cual, con la finalidad de poder comparar con otras escalas territoriales, establecemos el factor de mutiplicar X2 el número de habitaciones. ${ }^{2}$ El valor de la oferta total de 
plazas para cada categoría de establecimiento utilizado para calcular los porecentajes es el reflejado en el Directorio de empresas e actividades turísticas, Dirección Xeral para o Turismo, Consellería de Cultura e Turismo. Datos referidos al 31 de Diciembre de 2012.

\subsection{La oferta turística residencial}

La oferta turística en la última década se vio marcada desde el punto de vista de su ordenación territorial por un acelerado proceso de urbanización y construcción en el litoral gallego. Un proceso que únicamente se paralizó por los efectos de la crisis económica vinculada al estallido de la burbuja inmobiliaria a finales del año 2007. Las múltiples derivaciones que eso comporta, y que superan las meramente turísticas, demandan un ejercicio urgente de reflexión por parte de los gestores de las OMDs para conocer los diferentes impactos socioeconómicos como de orden ambiental que de eso se derivaron a corto plazo, así como para valorar la competitividad a medio plazo de los distintos modelos de desarrollo que rigen en los diversos municipios turísticos del litoral, y la adecuación de esos espacios turísticos a unos clientes cada día más exigentes de unas experiencias más integrales.

El atractivo y competitividad de cualquer destino turístico derivará en buena parte de cual sea el nivel y equilibrio entre las diversas categorías y tipologías de alojamiento. Y sobre todo, como se integre con los diversos servicios complementarios en la conformación de la denominada cadena de valor, así como también las experiencias que se materializan en los mismos. En paralelo, también influye la ordenación territorial y las condiciones del entorno en el que se insertan. La realidad es que en las últimas décadas, en un bueno número de municipios del litoral gallego se generalizaron dinámicas que desembocaron en entornos sometidos a un urbanismo extensivo, y que indujeron a posicionamientos turísticos más bien indiferenciados. En definitiva, una excesiva presión urbanizadora amparada en los altos rendimientos que a corto plazo generaba la promoción inmobiliaria hasta el estallido de la burbuja inmobiliaria. Un proceso urbanizador que condicionó la competitividad de sus recursos naturales y patrimoniales de un buen número de municipios del litoral gallego, poniendo en riesgo la capacidad de sus infraestructuras y sistemas para garantizar los mayores empleos y una renta sostenible.

Los gestores de las OMDs del litoral gallego deben ser conscientes de las potencialidades turísticas de sus territorios con el objeto de configurar un modelo de desarrollo turístico acorde y diferenciado. Un modelo que debe huir del excesivo incremento de la superficie urbanizada de carácter residencial. Unas residencias secundarias que constituyen sin ningún tipo de duda el elemento del paisaje que mejor define y peculariza el proceso de producción de espacio de ocio en amplios ámbitos territoriales del litoral gallego. Un modelo de crecimiento basado en la construcción de residencias secundarias que hacen la competencia a la oferta re- 
glada, responde a un esquema en el que la especulación urbanística propició que la oferta de camas vaya por delante de la demanda, lo que junto a la existencia de una importante oferta ilegal y desleal repercute en unos bajos precios y escasa calidad de la oferta hotelera. Situación que demanda desde las OMDs una más que necesaria planificación que aborde todos estos aspectos. Planificación no circunscrita únicamente a los problemas urbanísticos directamente derivados de la proliferación de la segunda residencia, sino que abarque todo el ámbito territorial del destino turístico en cuestión. No olvidemos la importancia que dentro del producto turístico tiene el mantener unos elevados niveles de calidad ambiental, para lo cual se hace preciso establecer una serie de medidas que ordenen y limiten la ocupación del territorio, ya que al sobrepasar un determinado umbral de capacidad de carga se producirá automáticamente un deterioro de la calidad de la experiencia turística.

\subsubsection{La oferta de residencias secundarias}

La expansión del uso residencial del suelo de las residencias secundarias, tiene una clara proyección espacial en las modificaciones inscritas desde inicios del siglo XXI en la organización del territorio litoral gallego. Un litoral que estuvo alejado tradicionalmente del desarrollo urbanístico residencial ligado al producto turístico de "sol y playa", salvo sectores muy concretos (margen norte de la Ría de Pontevedra, los municipios de Baiona y Nigrán en la órbita urbana de Vigo; Oleiros y Sada en la zona de influencia de la ciudad de A Coruña, etc.), lo que le concedió cierta singularidad dentro del conjunto que conforma el litoral español. De hecho, debido básicamente a su enclavamiento territorial, el litoral gallego salió casi intacto de la fiebre inmobiliaria de los años 80 y 90, que destrozó otras zonas españolas del litoral. Galicia era una zona recóndita y de muy difícil acceso con unos tiempos de viaje elevados y con unas carreteras que se situaban a la cabeza en índices de siniestralidad. Esta situación de seudo-aislamiento se mantuvo hasta la total finalización en el año 2002 de las autovías del NO y la de la Rías Baixas. Esto junto con el comienzo en la mejora de la red viaria interior aliviaron en gran parte los problemas de aislamiento y mala comunicación. Unas circunstancias que propiciaron mayores dessarrollos inmobiliarios en el espacio litoral. Un litoral donde el precio era sensiblemente inferior al de otros puntos litorales españoles. Fue a partir de entonces cuando en las Rías Baixas, la Costa da Morte, la Mariña Lucense, comenzaron a florecer urbanizaciones de carácter turístico residencial. Este proceso de crecimiento de las residencias secundarias se plasmó en uno deterioro del paisaje tradicional y en una excesiva concentración del espacio construido en determinados lugares concretos, de buena imagen turística y adecuada accesibi- 
lidad. Una realidad que queda plenamente reflejada en la evolución del número de residencias secundarias ${ }^{18}$ durante el período intercensal 2001-2011. En Galicia este crecimento fue del 33,89\% (Cuadro 3). El litoral gallego, en su conjunto, pasó de albergar 214.790 residencias secundarias en el año 2001 a concentrar 266.312 en el 2011. Una evolución que representa un incremento del 23,99\%. Ahora bien, dentro del conjunto del litoral tanto a nivel de espacios turísticos como municipal, observamos comportamientos constrastados.

\begin{tabular}{|c|c|c|c|}
\hline \multicolumn{4}{|c|}{$\begin{array}{c}\text { Cuadro 3. Evolución del número de viviendas secundarias }{ }^{1} \text { en Galicia, a nivel provincial, en los } \\
\text { espacios turísticos del litoral gallego. Período } 2001-2011 . \text { Unidad: Número de viviendas. }\end{array}$} \\
\hline & 2001 & 2011 & $\Delta \%$ \\
\hline A Marińa Lucense & 11.736 & 20989 & 78,84 \\
\hline Ortegal & 6210 & 9992 & 60,9 \\
\hline Golfo Ártabro & 78.568 & 88.166 & 12,22 \\
\hline Costa da Morte & 16.113 & 22.600 & 40,26 \\
\hline Ría de Muros-Noia & 7.491 & 9.544 & 27,41 \\
\hline Ría de Arousa & 15.009 & 24.808 & 65,29 \\
\hline Ría de Pontevedra & 28.871 & 32.865 & 13,83 \\
\hline Ría de Vigo & 45.384 & 50.742 & 11,81 \\
\hline Baixo Miño & 5.408 & 6606 & 22,15 \\
\hline LITORAL GALLEGO & 214.790 & 266.312 & 23,99 \\
\hline A Coruña & 161.262 & 206.262 & 27,90 \\
\hline Lugo & 61.471 & 88.158 & 43,41 \\
\hline Ourense & 70.402 & 111.985 & 59,07 \\
\hline Pontevedra & 114.852 & 139.843 & 21,76 \\
\hline Galicia & 407.987 & 546.248 & 33,89 \\
\hline
\end{tabular}

Fuente: Elaboración propia a partir del INE: “Censo de población y vivendas” de los años 2001 y $2011 .{ }^{1}$ Consideramos como viviendas secundarias a las incluidas en el Censo de Poboación y Vivendas como "no principales" (secundarias+vacías)".

18 Antes de continuar ahondando en nuestro análisis, creemos oportuno señalar que nos encontramos ante una tipología de alojamiento turístico de difícil aproximación, dado que carecemos de información actualizada sobre el parque de viviendas de potencial uso turístico, y se carece de los elementos de valor para deducir cuáles son disfrutadas como tales. A los efectos de este estudio, siguiendo las pautas de DELOITTE/EXCELTUR (2005), realizamos una aproximación al parque de viviendas que por sus condiciones y localización se pueden utilizar turísticamente. Con tal objeto, a lo largo del presente estudio de investigación, consideraremos como residencias secundarias no solo a aquellas que fueron declaradas como segundas residencias, si no también a todas aquellas vacías en el momento de realizarse el Censo de Población y Viviendas por parte del INE. DELOITTE/ÁREA DE ESTUDIOS E INVESTIGACIÓN DE EXCELTUR (2005): "Impactos sobre el entorno, la economía y el empleo de los distintos modelos de desarrollo turítico del litoral Mediterráneo español, Baleares y Canarias: Sumariom ejecutivo”. Exceltur, Madrid; op. cit. pág. 20. 
Atendiendo a los valores sobre residencias secundarias recogidos en el Censo de Población y Viviendas 2011 (INE) elaboramos una serie de indicadores de presión con el objeto dimensionar territorialmente la oferta turística residencial en el ámbito litoral gallego. Empezaremos apuntando que en el año 2011 había censadas en el conjunto del litoral gallego 264.524 residencias de carácter secundario, lo que implica una oferta total de 1.065 .248 plazas $^{19}$ (48,43\% del total en Galicia). Una cifra de residencias secundarias que supone que el 30,68\% de la viviendas en el litoral tenga carácter secundario, una densidad de 54,28 residencias secundarias/ $\mathrm{km}^{2}$ y una Tasa de Función Residencial (T. F. R.) del 44,28. Los espacios turísticos del litoral gallego con mayor oferta de plazas en residencias secundarias son (Cuadro 4): Golfo Ártabro (352.664 plazas, 33,11\% y 16,14\% del total del conjunto del litoral gallego y Galicia, respectivamente), Ría de Vigo (202.968 plazas, 19,05\% y 9,29\% del total del conjunto del litoral gallego y Galicia, respectivamente) y Ría de Pontevedra (131.460 plazas, 12,34\% y 6,02\% del total del conjunto del litoral gallego y Galicia, respectivamente). En los dos primeros espacios, estos altos valores responden a localizar dentro de su sector litoral a los municipios urbanos de A Coruña (119.308 plazas, $11,20 \%$ y 5,46\% del total del conjunto del litoral gallego y Galicia, respectivamente), Ferrol (46.764 plazas, 4,39\% y 2,14\% del total del conjunto del litoral gallego y Galicia, respectivamente) y Vigo (116.496 plazas, 10,94\% y $5,33 \%$ del total del conjunto del litoral gallego y Galicia, respectivamente). La oferta residencial de la Ría de Pontevedra responde a una mayor especialización turística centrada en el producto "sol y playa," como demuestran los indicadores de "\% de viviendas secundarias sobre total" $(35,54)$ y de T. F. R. $(55,14)$. De hecho, en esta Ría se encuentra el municipio de Sanxenxo, de marcada vocación turística residencial (44.236 plazas, 4,15\% y 2,02\% del total del conjunto del litoral gallego y Galicia, respectivamente). Una vocación que queda patente en el 0,62 de su indicador "plazas en residencias por población de hecho" como en el valor de su T. F. R. $(189,50)$. Un promedio superado solo por los muncipios de Barreiros $(1,13)$ y Foz $(0,64)$. Territorios localizados en la Mariña Lucense que sufrieron un auténtico "boom inmobiliario" turistico residencial a inicios del siglo XXI como testimonia

19 A cada una de las potenciales residencias secundarias le computamos una capacidad de alojamiento de cuatro plazas por vivienda con el objeto de poder aproximarnos a los potenciales niveles de presión humana que inducen sobre el medio del espacio litoral. Se trata de un valor de asignación empleado y asumido en otros trabajos efectuados. Véase: PATIÑO ROMARÍS, C. A. (2001). "Espacios turísticos e de ocio nas Rías Baixas: Unha análise a diferentes escalas”. Direción Xeral para o Turismo, Consellería de Cultura, Comunicación Social e Turismo, Xunta de Galicia, Santiago de Compostela. PATIÑO ROMARÍS, C. A. (2002a): "A illa da Toxa: O planeamento urbanístico no proceso de construcción e transformación dun producto turístico litoral”. Servicio de Publicacións da Deputación Provincial de Pontevdra, Vigo. 
el incremento de viviendas secuncarias registrado en el Censo de Población y Viviendas de 2011 (122,62\% y 147,78\%, respectivamente).

\begin{tabular}{|c|c|c|c|c|c|c|c|c|}
\hline \multicolumn{2}{|c|}{ Cuadro 4.- Oferta turística residencial en los espacios turísticos del litoral gallego. Año 2011.} \\
\hline & $\begin{array}{c}\text { Número de } \\
\text { viviendas } \\
\text { secundarias }\end{array}$ & $\begin{array}{c}\text { \% viviendas } \\
\text { secundarias } \\
\text { sobre total }\end{array}$ & $\begin{array}{c}\text { Densidad } \\
\text { (viviendas } \\
\text { por Km²) }\end{array}$ & $\begin{array}{c}\text { Residencias } \\
\text { secundarias/ } \\
\text { Población de } \\
\text { hecho }\end{array}$ & T.F.R. ${ }^{2}$ & $\begin{array}{c}\text { Oferta plazas } \\
\text { residencias } \\
\text { secundarias }\end{array}$ & $\begin{array}{c}\% \text { sobre } \\
\text { total del } \\
\text { litoral }\end{array}$ & $\begin{array}{c}\text { \% Total } \\
\text { Galicia }\end{array}$ \\
\hline $\begin{array}{c}\text { A Marińa } \\
\text { Lucense }\end{array}$ & 20.989 & 47,38 & 28,97 & 0,35 & 90,13 & 83.956 & $7,88 \%$ & $3,84 \%$ \\
\hline Ortegal & 9.992 & 48,76 & 19,48 & 0,38 & 95,23 & 39.968 & $3,75 \%$ & $1,83 \%$ \\
\hline $\begin{array}{c}\text { Golfo } \\
\text { Ártabro }\end{array}$ & 88.166 & 27,30 & 103,49 & 0,16 & 37,57 & 352.664 & $33,11 \%$ & $16,14 \%$ \\
\hline $\begin{array}{c}\text { Costa da } \\
\text { Morte }\end{array}$ & 22.600 & 40,29 & 20,07 & 0,24 & 67,52 & 90.400 & $8,49 \%$ & $4,14 \%$ \\
\hline $\begin{array}{c}\text { Ría de } \\
\text { Muros-Noia }\end{array}$ & 9.544 & 39,41 & 31,35 & 0,23 & 65,10 & 38.176 & $3,58 \%$ & $1,75 \%$ \\
\hline $\begin{array}{c}\text { Ría de } \\
\text { Arousa }\end{array}$ & 24.808 & 32,94 & 60,21 & 0,17 & 49,13 & 99.232 & $9,32 \%$ & $4,54 \%$ \\
\hline $\begin{array}{c}\text { Ría de } \\
\text { Pontevedra }\end{array}$ & 32.865 & 35,54 & 114,63 & 0,20 & 55,14 & 131.460 & $12,34 \%$ & $6,02 \%$ \\
\hline Ría de Vigo & 50.742 & 24,40 & 138,79 & 0,12 & 32,29 & 202.968 & $19,05 \%$ & $9,29 \%$ \\
\hline Baixo Mińo & 6.606 & 27,20 & 20,46 & 0,13 & 37,37 & 26.424 & $2,48 \%$ & $1,21 \%$ \\
\hline $\begin{array}{c}\text { LITORAL } \\
\text { GALLEGO }\end{array}$ & 266.312 & 30,68 & 54,28 & 0,17 & 44,28 & 1.065 .248 & $100 \%$ & $48,75 \%$ \\
\hline
\end{tabular}

Fuente: Elaboración propia a partir del INE: Padrón municipal de habitantes (2012) y Censo de Población y Viviendas (2011). Datos superficie km² IGN (Instituto Geográfico Nacional). ${ }^{1}$ Consideramos como viviendas secundarias a las incluidas en el Censo de Población y Vivendas como "no principales (secundarias+vacías)". ${ }^{2}$ T.F.R. = Rs X 100 / Rp, donde: TFR es la Tasa de Función Residencial; Rs es el número de viviendas secundarias; Rp es el número de viviendas principales. ${ }^{3}$ Oferta plazas en residencias secundarias $=n^{\circ}$ viviendas secundarias $X 4$.

\subsection{Oferta total de alojamiento e indicadores de presión sobre el litoral gallego}

El conjunto del litoral gallego en el año 2012 concentraba un total 1.148 .070 plazas potenciales de alojamiento turístico (49,60\% del total de Galicia). Un volumen de oferta de alojamiento que viene a suponer: 0,73 plazas/habitante y 233,98 pla$\mathrm{zas} / \mathrm{Km}^{2}$. Un indicador de presión, este último, muy expresivo de la importancia del sector turístico litoral dentro de Galicia. No en vano, el valor de este indicador duplica ampliamente el resultado obtenido para el conjunto del territorio gallego. Por otra parte, la oferta de alojamiento dentro del litoral gallego se centra esencialmente en las viviendas de carácter secundario $(92,79 \%$ del total de la oferta de alojamiento). Una realidad que se tradujo en problemas de degradación ambiental en determinados sectores del litoral. En el Mapa 3, con datos del año 2012, indivi- 
dualizamos los distintos espacios turísticos definidos dentro del litoral gallego en función de las características esenciales de su oferta de alojamiento y los indicadores de presión de la misma.

\section{Mapa 3.- Distribución de la oferta total de alojamiento en los municipios del litoral gallego: Indicadores de presión. Año 2012.}

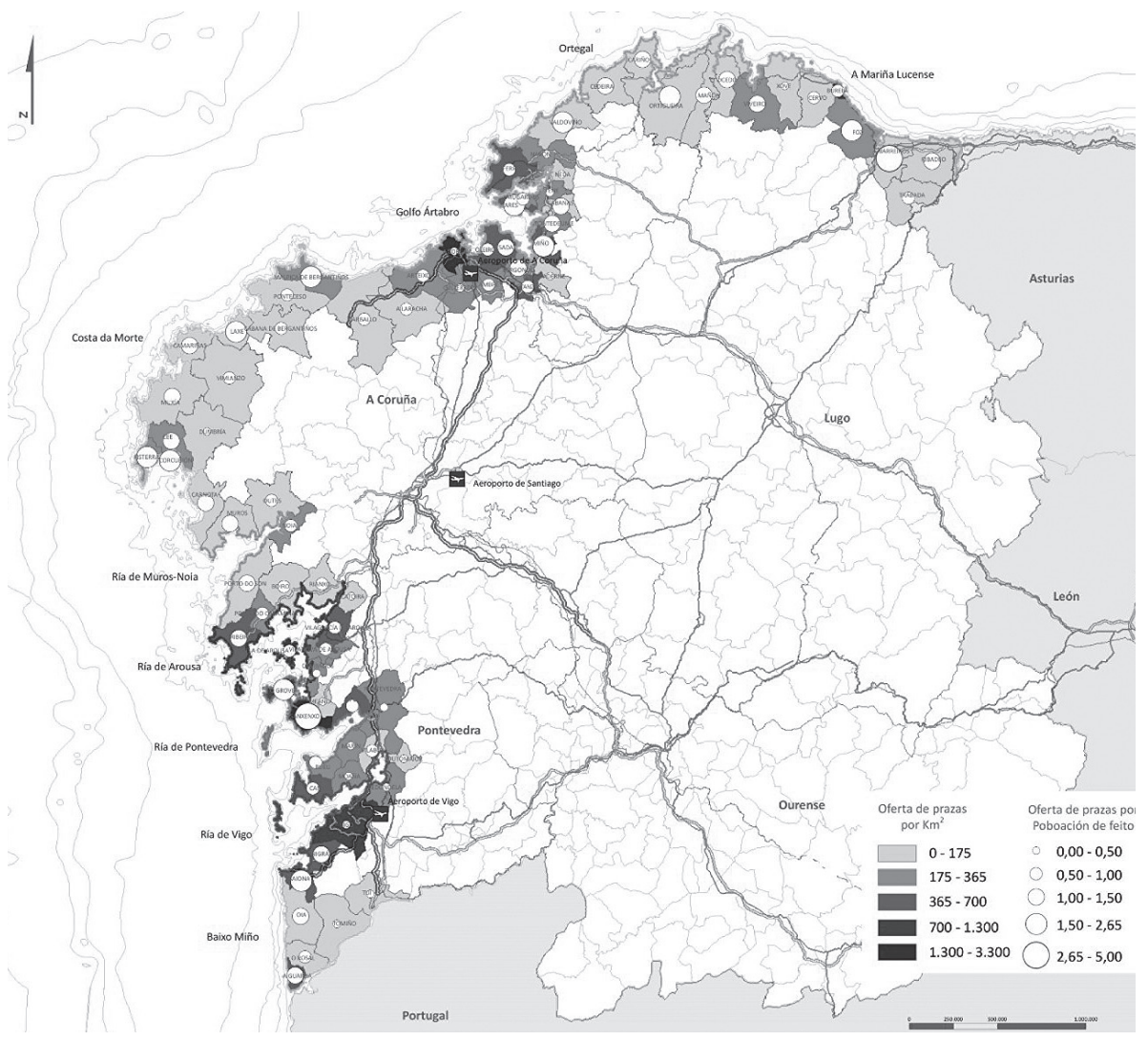

Fuente: Elaboración propia.

\subsection{Productos turísticos diferenciadores y emergentes de la oferta turística del litoral gallego}

El modelo clásico de turismo en el litoral gallego cambió en la última década, emergiendo productos complementarios al hasta ahora producto estrella, sol y playa. La creación de nuevos productos se formuló como una de las vías para el mantenimiento de la competitividad de los destinos turísticos del litoral, ya que generan efectos positivos como el aumento de la satisfacción de los visitantes y del gasto en destino, la reducción de la estacionalidad o la creación de nuevas 
opciones de negocio ${ }^{20}$. De hecho, se produjo una diversificación en la oferta, apareciendo nuevos productos turísticos como pueden ser: el turismo náutico, naturaleza, mariñeiro, etc. ${ }^{21}$. La oferta turística del litoral gallego se caracteriza actualmente por su diversidad y complementariedad. Frente a otros destinos turísticos monoproducto, el litoral gallego posee una notable variedad y singularidad de recursos, tanto naturales como etnográficos ${ }^{22}$, en un espacio territorialmente pequeño. Ahora bien, no todos estos recursos pueden considerarse como producto turístico, ya que pueden no estar disponibles para su uso o no poseer un interés potencial claro. No se encuentran estructurados de manera que puedan presentarse al visitante como un producto turístico individualizado. Las OMDs son las que deben integrar y organizar los diferentes componentes de la oferta de un territorio para estructurar productos diferenciados que respondan a las necesidades y motivaciones de diferentes mercados y segmentos. La complejidad de la cadena del producto turístico exige que se formulen acciones dirigidas a mejorar cada uno de los pasos, desde la planificación y la creación de producto o la programación, hasta la promoción y la comercialización. Una labor de creación y desarrollo de nuevos productos turísticos que dentro del litoral gallego se constituyó en una de las principales estrategias de actuación por parte de los entes tanto públicos como privados ${ }^{23}$. Unas actuaciones que tienen como fin la reestructuración de la obsoleta cartera de productos ofrecida por los destinos del litoral gallego. Una oferta basada casi exclusivamente en el producto "sol y playa". Así como, hacer frente a las nuevas megatendencias observadas dentro el mercado de demanda, donde son especialmente significativas las novedosas y cambiantes necesidades y motivaciones del consumidor turístico.

En definitiva, esta situación determina la necesidad, desde las OMDs del litoral gallego, de poner en funcionamiento políticas que redefinan los productos turísticos por medio de la introducción de elementos enriquecedores de la denominada oferta turística complementaria como un argumento favorecedor de la calificación, diversificación y diferenciación de estos. En este sentido, están también aquellos esfuerzos encaminados a potenciar segmentos turísticos de mayor valor añadido. La puesta en funcionamiento de estas medidas revitalizadoras lleva

20 Véase: Anton Clavé, S. (2004): "De los procesos de diversificación y cualificación a los productos turísticos emergentes. Cambios y oportunidades en la dinámica reciente del turismo litoral”. Papeles de Economía Española, no 102; pp. 316-333. Priestley, G. y Llurdés, J.C. (2007): "Planning for sustainable development in Spanish coastal resorts", en Agarwal, S. y Shaw, G. (eds.): "Managing coastal tourism resorts. A global perspective". Channel View Publications, Clevedon (U.K.); pp. 90-111.

21 Peñalver Torres, M. T. (2004): 180.

22 Padín Fabeiro, C. y Aboy García, S. (2010): 59.

23 Ulla Lorenzo, F. y Pazos Otón, M. (2010): 43. 
consigo la necesaria implementación de dos tipos de actuaciones, que podemos calificar como ${ }^{24}$ :

- Actuaciones de potenciación y desarrollo de nuevos productos. Para lo cual es esencial conocer, valorar y aprovechar los recursos propios de un espacio por medio de diseños operativos, relacionados, por ejemplo, con el turismo rural, activo, etc.

- Acciones de reacondicionamento de espacios turísticos consolidados, dentro de las cuales se inscriben intervenciones de dotación y mejora de equipaciones y servicios, reordenación de bordes marítimos, reapertura al mar de las poblaciones y técnicas de esponjamiento y de recuperación de áreas portuarias degradadas. Entre este tipo de actuaciones se incluyen aquellas orientadas a la creación de nuevos elementos de oferta complementaria, entre las cuales se encontrarían, a modo de ejemplo, las encaminadas a la creación o mejora de los puertos deportivos y a la puesta en valor de todas aquellas actividades englobadas dentro del término turismo náutico.

\section{Recapitulación final}

El conjunto del litoral gallego se caracteriza aún en la actualidad por un desarrollo turístico muy escaso en comparación con el que ocurre en otras zonas del mediterráneo español. Se trata de un sistema poco integrado en los circuitos comerciales y que espacialmente se plasma en modelos de ocupación extensivos, con predominio de un desarrollo inmobiliario de carácter secundario y lastrado por una fuerte estacionalidad. Ante esta realidad, los gestores de las diferentes OMDs del litoral gallego deben seguir apostando por el turismo desde un modelo de desarrollo sostenible. Un modelo en el que la oferta de alojamiento se oriente prioritariamente hacia las plazas de hotel de calidad, centradas en estancias cortas basadas en productos turísticos de carácter diferenciador que reduzcan la estacionalidad y proporcionen un posicionamiento más favorable dentro del mercado de demanda a un territorio con escasa tradición turística, salvo sectores muy concretos del litoral. Unos sectores del litoral gallego (margen norte de la Ría de Pontevedra, Golfo Ártabro, etc.), que están en una situación de elevado grado de saturación y falta de calidad. Son espacios degradados, particularmente en lo ambiental, cuya consecuencia en el mercado turístico puede ser la pérdida de competitividad. Frente a eso, proponemos un cambio de modelo y de enfoque que desde el cuidado del entorno y la sostenibilidad ambiental favorezca una ra-

24 Patiño Romarís, C. A. (2004b): 7 y 8. 
lentización de la urbanización en el conjunto del litoral gallego, primando, por un lado, aquellas combinaciones entre oferta reglada y residencial que aporten los mayores efectos de índole socioeconómica y el mayor valor añadido a largo plazo a los destinos. Y dinamizando, por otra parte, la propia actividad constructiva apostando más decididamente por la rehabilitación de los espacios urbanos y zonas de esparcimiento, así como invirtiendo en infraestructuras y dotación de equipaciones que complementen y diferencien los atributos y atractivos del litoral. Aceptar el desafío que comportan esos nuevos principios supone, sin duda, un cambio de orientación en el que fueron algunos de los paradigmas que rigieron durante las últimas décadas la cultura y los modelos de gestión del desarrollo del turismo en el litoral gallego, imponiendo desde las OMDs un modelo de gestión basado en la gobernanza. Un modelo de gestión que aporte una nueva óptica y un nuevo marco de actuación y cooperación entre los agentes públicos y privados, sustentado en un mayor consenso y complicidad de la propia sociedad local.

La situación dibujada en el litoral gallego contrasta con la realidad del sector turístico a escala global, la cual experimenta transformaciones estructurales derivadas de los nuevos patrones de producción y comercialización, los cambios en la demanda y una mayor exigencia del turista que reclama calidad en los productos y servicios, al tiempo que se preocupa por los impactos de la actividad. En este aspecto, en la actualidad el litoral gallego como destino turístico está conformado por una serie de productos turísticos diferenciados ("sol y playa", náutico, mariñeiro, etc.). Productos que se caracterizan por un grado propio de magnitud, de calidad y por encontrarse en una fase concreta del ciclo de vida de un producto. Las OMDs deben tener claro que el estudio del estado y naturaleza de estos productos debe suponer el punto de partida para la elaboración de cualquier tipo de planificación de carácter estratégico. Estudio que debe realizar una diagnosis del estado del destino turístico, descubrir los puntos fuertes y los que deben mejorarse. También creemos necesario el denominado análisis comparativo que nos informará de aquellos aspectos positivos o negativos que se habían podido dar en otros espacios turísticos, para poder hacer uso convenientemente de la dicha experiencia a la hora de diseñar las acciones a implementar dentro del marco estratégico definido. Acciones a impulsar desde las OMDs, las cuales deben procurar evidentemente la consecución de ventajas competitivas con respeto a los competidores potenciales. Competitividad, que en un mercado turístico actual cada vez más segmentado y en evolución constante, está muy relacionado con la capacidad de innovar y dar alternativa a nuevos productos o semiproductos (que enriquezcan la oferta de modalidades tradicionales), la disponibilidad de una oferta complementaria lo más amplia posible y la calidad de los servicios prestados. Estas variables permiten la diferenciación de la imagen de un destino con respecto a otros poten- 
cialmente competidores. En definitiva, impulsar y garantizar el atractivo de un destino turístico, evitando en la medida de lo posible aspectos negativos como lo de la estacionalidad.

Otro aspecto relevante a tener presente por parte de las OMDs a la hora de diseñar y poner en funcionamiento cualquier tipo de planificación de carácter turístico, es que el turismo no es una actividad específica y aislada, sino la suma de varias ramas de actividad, de administraciones públicas, infraestructuras y servicios complementarios específicos y generales ${ }^{25}$. En este mismo sentido, sería de gran interés analizar el potencial y el impacto económico real, directo e indirecto, de los diferentes productos turísticos sobre su ámbito inmediato; lo cual resulta de muy difícil evaluación, aunque en todo caso, el primer paso preciso es determinar y establecer un sistema de indicadores socioeconómicos válido a cualquier producto, con el objeto de poder realizar los oportunos estudios comparativos, a través de los cuales poder llegar a un mejor conocimiento de la realidad del sector. Los gestores deben tener presente que en turismo las diferentes actuaciones formuladas con carácter sectorial deben guardar coordinación con el modelo turístico establecido. Es decir, las OMDs deben tener muy presente que cada actuación implica unos beneficios y unos costes que se deben ponderar con antelación. En cualquier caso, la planificación de los productos turísticos deberá procurar en todo momento la consecución de una racionalidad inversora, orientada a mejorar la calidad de la comercialización de la oferta con respeto a la demanda potencial.

25 Vera Rebollo, J. F. y Marchena Gómez, M. (1990): 62. 


\section{Bibliografía}

Álvarez Sousa, A.; Gónzalez Vázquez y Varela González, J. A. (2005): Plan de Ordenación del Turismo de Galicia. POTGA 2005-2010, Santiago de Compostela Dirección Xeral de Turismo, Consellería de Cultura, Comunicación Social e Turismo, Xunta de Galicia.

Anton Clavé, S. (2004): "De los procesos de diversificación y cualificación a los productos turísticos emergentes. Cambios y oportunidades en la dinámica reciente del turismo litoral", Papeles de Economía Española, 102: 316-333.

Argimón, I. y González-Páramo, J. M. (1997): “Efectos de la inversión en infraestructuras sobre la productividad y la renta de las CC.AA.: Especial referencia al tranporte por carretera en Galicia”, en Pérez Touriño, E. (dir.): Infraestructuras y desarrollo regional: Efectos económicos de la Autopista del Atlántico, Madrid, Civitas: 141182.

Argimón, I.; González-Páramo, J. M.; Martín, Mª J. y Roldán, J. Mª (1993): Productividad e infraestructuras en la economía española. Documento de Trabajo nº 9313 , Madrid, Banco de España

Ashworth, G. J. y Dietvorst, G. J. (ed.) (1995): Tourism and Spatial Transformations: Implications for Policy and Planning, Wallingford (U.K.),CAB International.

Ávila Bercial, R. y Barrado Timón, D. A. (2005): "Nuevas tendencias en el desarrollo de destinos turísticos: Marcos conceptuales y operativos para su planificación y gestión”, Cuadernos de Turismo, 15: 27-43.

Biehl, D. (1988): "Infraestructuras y desarrollo regional”, Papeles de Economía Española, 35: 293-310.

Bigné Alcañiz, J. E.; Font Aulet, X. y Andreu Simó, L. (2000): "Marketing de destinos turísticos: Análisis y estrategias de desarrollo, Madrid, ESIC Editorial.

Díaz Fernández, J. A. (2000): "La participación de los sistemas de transportes y comunicaciones en el desarrollo de la actividad turística en Galicia”, en Hernández Borge, J.; Díaz Fernández, J. A. y Patiño Romarís, C. A. (coords.): O Turismo en Galicia. Potencialidades endóxenas de desenvolvemento urbano e económico, Vigo, Servicio de Publicaciones de la Diputación Provincial de Pontevedra: 21-84.

Díaz Fernández, J. A. (2009): "La política de infraestructuras del transporte y las comunicaciones en Galicia: el estado de la cuestión”, en González Laxe, F. I. (dir.): La economía de Galicia. Proyecto Galicia. Tomo II, A Coruña, Edit. Hércules Ediciones: 257-409.

Díaz Fernández, J. A. y Patiño Romarís, C. A. (2010): "La accesibilidad territorial a los parques naturales de Galicia: aproximación a un factor estratégico para la dinamización turística”, Revista de Desarrollo Rural y Cooperativismo Agrario, 12: 183.204. 
Dredge, D. y Moore, S. (1999): "Planificación y Diseño de Destinos Turísticos". Annals of Tourism Research en Español”, 1(2): 394-414.

González Laxe, F. I. (coord.) (1993): Estructura económica de Galicia, Madrid, Edit. Alianza.

Gunn, C. A. (1972): Vacationscape: Designing tourist Regionans, Austin (USA), Bureau of Business Research, University of Texas.

Gunn, C. A. (1988): Tourism Planing, New York, Taylor \& Francis.

Gunn, C. A. (1993): Tourism Palanning: Basics, Concepts, Cases, Washington, D.C., Taylor \& Francis.

Hernández Borge, J.; Díaz Fernández, J. A. y Patiño Romarís, C. A. (coords.) (2000): O turismo en Galicia: Potencialidades endóxenas de desenvolvemento urbano e económico, Vigo, Servicio de Publicaciones de la Diputación Provincial de Pontevedra.

Izquierdo de Bartolomé, R. (1989): Las carreteras españolas, Madrid, SEOPAN.

Kotler, P.; Bowen, J.; Makens, J.; Rufin Moreno, R. y Reina Paz, M. D. (2004): Marketing para turismo, Madrid, Pretince Hall-Pearson Educación, S. A.

Kotler, P. y Keller, K. L. (2006): Marketing Management, Upper Saddle River (New Jersey-USA), Pearson/Prentice Hall.

Labasse, J. (1987): La ordenación del espacio, Madrid, Edit. IEAL.

Padín Fabeiro, C. y Aboy García, S. (2010): "Nuevos productos turísticos: La apuesta por el turismo marinero en Galicia”, Revista de Estudos Politécnicos, VIII (14): 5583.

Patiño Romarís, C. A. (2000): A producción de espacio turístico e de ocio na marxe norte da Ría de Pontevedra, Santiago de Compostela, IDEGA (Instituto Universitario de Estudios e Desenvolvemento de Galicia), Servicio de Publicacións da Universidade de Santiago de Compostela.

Patiño Romarís, C. A. (2001): Espacios turísticos e de ocio nas Rías Baixas: Unha análise a diferentes escalas, Santiago de Compostela, Dirección Xeral para o Turismo, Consellería de Cultura, Comunicación Social e Turismo, Xunta de Galicia.

Patiño Romarís, C. A. (2002a): A illa da Toxa: O planeamento urbanístico no proceso de construción e transformación dun produto turístico litoral, Vigo, Servicio de Publicacións da Deputación Provincial de Pontevdra.

Patiño Romarís, C. A. (2002b): "Los espacios naturales protegidos de Galicia como focos de atracción turística: el Parque Natural del "Complexo dunar de Corrubedo e Lagoas de Carregal e Vixán”, en Turismo y transformaciones urbanas en el siglo XXI, Almería, Universidad de Almería. Almería: 313-324.

Patiño Romarís, C. A. (2004a): "As infraestruturas de transportes na demanda turística”, en Díaz Fernández, J. A. y Lois González, R. C. (dir.): Las infraestructuras de comunicaciones y transportes en el desarrollo territorial de Galicia, Pontevedra, Servicio de Publicaciones de la Diputación Provincial de Pontevedra: 481-523. 
Patiño Romarís, C. A. (2004b): El turismo náutico en Galicia: La oferta de puertos deportivos, A Coruña, Monografías. Instituto Universitario de Estudos Marítimos (IUEM), Universidade da Coruña.

Patiño Romarís, C. A..; Díaz Fernández, J. A. y Sánchez Pavón, B. (2005): El turismo náutico y los puertos deportivos: Planificación y potencialidades económicas, Santiago de Compostela, Autoridade Portuaria de A Coruña.

Peláez Verdet, A. (2002). Puertos deportivos: Repercusión de su administración y gestión en el desarrollo del turismo náutico. Estrategias para el caso de la Costa del Sol, Málaga, Tesis doctoral, Departamento de Economía y Administración de Empresas, Universidad de Málaga.

Penas Murias, M. V. (1987): El Área de Oleiros-Sada: Un espacio de ocio en la periferia de La Coruña, A Coruña, Excma. Diputación Provincial de La Coruña.

Peñalver Torres, M. T. (2004): "El turismo activo como alternativa y complemento al modelo turístico en la Región de Murcia”, Cuadernos de Turismo, 14:179-215.

Priestley, G. y Llurdés, J.C. (2007): "Planning for sustainable development in Spanish coastal resorts”, en Agarwal, S. y Shaw, G. (eds.): Managing coastal tourism resorts. A global perspective, Clevedon (U.K.); Channel View Publications: 90-111.

Santos Iglesias, M. V. (2002): El turismo en el Val Miñor. Transformaciones espaciales y socioeconómicas en el suroeste de la provincia de Pontevedra, Santiago de Compostela, Memoria de Licenciatura (Inédita), Departamento de Xeografía Aplicada, Facultade de Xeografía e Historia, Universidade de Santiago de Compostela.

Santos Solla, X. M. (coord.); Castellanos García, P.; Dopico Castro, J. Á. y Pena López, J. A. (2007): El sector hotelero en Galicia desde el punto de vista de la competencia, Estudo elaborado para o TGDC (Tribunal Galego de Defensa da Competencia), Universidade de A Coruña.

Shaw, G. y Williams, A. M. (2002): Critical issues in tourism. A geographical perspective, Oxford (U.K.), Blackwell Publishers Ltd.

Ulla Lorenzo, F. y Pazos Otón, M. (2010): "Productos y destinos turísticos emergentes en Galicia”, Revista de Estudos Politécnicos, 8 (14):21-43.

Vera Rebollo, F. f. (coord.); López Palomeque, F.; Marchena, M. J. y Anton Clavé, S. (2011): Análisis territorial del turismo y planificación de destinos turísticos, Valencia, Tirant lo Blanch.

Vera Rebollo, J. F. y Marchena Gómez, M. (1990): "Turismo y desarrollo. Un planteamiento actual”, Papers de turisme, 3: 59-84. 